\title{
Societal and organizational influences on integration: what about networking?
}

\author{
Betty Collis
}

Faculty of Educational Science and Technology

University of Twente, The Netherlands

\begin{abstract}
This paper reflects on the thesis that social and organizational forces have a great influence on the degree to which and the way in which the student encounters communication and information technologies in the secondary school. To expand on this thesis, a selection of social impulses that have served or are serving as a technology push in schools are considered, from "computer literacy" to "Internet literacy". As a counter force, some key aspects of the ways schools as organizations shape and constrain access to technology are reviewed. The movement toward "community networking" and "virtual networks" is considered as a current example of how complex social developments from outside education can influence the ways young persons and teachers experience communication and information technologies in schools. The likelihood of information technology becoming deep rooted enough to significantly affect educational practice is considered.
\end{abstract}

Keywords: networks, communication, future developments, innovation, social issues 


\section{INTRODUCTION: SCHOOLS IN THE YEAR 2000}

Visions and agendas for "schools in the year 2000" are beginning to appear in a number of countries. A conference in April 1994, for example, in the United States brought together nearly a thousand educational decision makers to discuss such an agenda. The assumption that was continually expressed throughout the meeting was one of radical change in education as it is now organized, moving from "buildings, lecturing, reading, and testing" toward the model of a "global village school":

"...a round-the-clock community of learners not necessarily bound by a place or building ... where learning occurs where it is appropriate: not only at its headquarters but also in the homes of its students, in the activities of its teams and clubs throughout a region, and in the far-flung sites that the student may reach by way of field trips and electronic connections". [1]

According to the speakers at this conference, the standard by which a student is judged to be well educated will be the extent to which he or she can effectively use the tools of the information age. Critical to such a vision, driving it as well as serving it, is the powerful metaphor of an "information superhighway".

To what extent is this vision being driven by forces - social, political, economic, philosophical - outside the professional education community? To what extent is the way in which the secondary-school student has the opportunity to make use of communication and information technologies influenced by such forces? It is part of the thesis of this paper that such "outside forces" exert a major influence on the educational deployment of communication and information technologies. This influence however is constrained by another powerful set of influences, the organization of secondary schooling itself, which also exerts a powerful effect (often a counter effect of resistance or inertia) on what happens with technology and the learner. This paper also briefly discusses some of these institutional influences.

In these two contexts, "networking" is seen as a powerful idea in society which is now gaining new impetus in terms of its potential influence on education and on the ways that communication and information technologies are applied in education. Is networking another example of an externally pushed idea shaping educational agendas, eventually to be neutralized by the resistance of the school as an 
organization? Or might networking emerge as being powerful enough educationally to bring a lasting change in the use of communication and information technologies in schools?

\section{SOCIETAL INFLUENCES ON COMMUNICATION AND INFORMATION TECHNOLOGIES IN SCHOOLS}

It can be argued that many major influences on the motivations for communication and information technologies in schools have not come from the educational community but from outside it. Five of these powerful ideas, two already losing momentum and three gaining power, are "computer literacy", "back to the basics", "equity and mobility", "cyberspace and the information superhighway", and "just-in-time learning".

\section{Computer literacy}

A number of analyses [see, for example, 2] have been done of the impetus for computers in schools and the phenomenon of "computer literacy", which moved at incredible speed throughout the world in the early 1980s and triggered mass-scale acquisition of computer hardware, software production, teacher training, new curriculum, and other manifestations. Generally these analyses show that calls for "computer literacy" were stimulated strongly by arguments such as "every child must be computer literate to be employable" and "schools must make sure students are computer literate in order for the larger society to maintain economic competitiveness".

Typical of the response to such societal pushes was for a country or region to put in place a large-scale effort to get computers into schools and to stimulate some initial training and software provision to accompany the arrival of the computers in the school. However, planning and provision for long-term support, on-going critical evaluation, and for the follow-up needed to bring teachers to the point of actually integrating computers as an established part of their teaching was often a second-layer of consideration, not part of the range of analysis of the initial computer-literacy advocates. The results can be seen in the frustratingly low levels of use of computers in secondary schools outside of courses that teach about computers [3]. But the social push of "computer literacy" was strong enough to set up an infrastructure in schools for computer use, a legacy which remains even as the external calls for being "computer literate" no longer much appear. 


\section{Back to the basics}

Another factor which has made a strong impact on education in general and on the use of information technology in particular is the reform-movement wave which regularly arises in different societies. One example in particular is the "back-to-the-basics" movement which was particularly influential in the United States but has had manifestations under different names in other cultures as well. "Back to the basics" was a reaction against "what was perceived as a growing liberalism and permissiveness among educators" while "wearing the mask of national interest and competitiveness" [4]. The driving agent of change was not educational analysis, but legislated reform stimulated by special interests, politics and economics [5]. The general assumption was that teachers were the problem; information technology was often seen, explicitly or implicitly, as a way to increase the efficiency of education, by providing better management and better designed instruction than the teacher was delivering with his or her resources. Although "back to the basics" has faded as a motivating buzzword in American circles, its influence still implicitly remains in terms of "integrated learning systems" and CMI (computer-managed instruction), and its social and organizational manifestations are still occurring in many countries, under movements called by names such as "accountability" and by mechanisms such as the publication of "league tables" that rank order schools on the basis of performance on standardized tests.

\section{Equity and mobility}

In contrast to the above two impulses, a theme which is currently very strong in Europe as well as the United States is that of providing equal opportunity for education (and later, for employment) regardless of the person's geographic location or personal circumstances. In Europe, this theme motivates many major initiatives; for example, the evolution of "flexible and open learning" and the idea of a "trans-European network for education and training" are explicitly based upon the policy goal of equal access throughout Europe to education and training [6]. In the United States the "vision" stimulating the emerging policy of the President's Executive Office of Science and Technology is stated as "To ensure every American access to excellence in education and training regardless of location, background, or personal situation" [7]. Both of these impulses have large political and social motivations and agendas. They also are explicitly based on the assumption that such equity and mobility will result in a stronger workforce and a more productive economy. Few of the prominent policy shapers appear to be from educational backgrounds. 
A direct consequence of these equal-access impulses is the expanding interest in more flexible learning opportunities, including a heightened interest in distance education, in that flexibility of time and place become necessary if equity in opportunity is to be developed. Communications technologies in particular are a major strategic key in providing flexible access to quality education, and as such are central now to a great number of initiatives in Europe, North America, Australia, and throughout the world. Institutions with well-developed distance education systems are now being joined by traditional educational institutions wishing to diversify and broaden their offerings, with the link between them being the use of communications technologies.

\section{Cyberspace and the information superhighway}

Another impulse which in the last year has burst forth in the popular media is the idea of cyberspace and the information highway. Although these terms are metaphors, they are powerful ones and suddenly are being taken seriously by society around the world. A large reason for this is the popular discovery of the Internet system, a network of networks sharing a common protocol which has been in existence for nearly 30 years but within the last one or two years has suddenly become a "household word". The number of networks in the system has doubled between 1992 and 1993, a new network is said to be connecting every ten minutes, and perhaps 20 million people now have access to the system. A sense of exhilaration stimulates many of those discovering this "cyberspace", a sense of "the freedom of the open road" to cite one of the many cliches now appearing. Not being able to be freely and equally connected to the Internet system or other networks is now being seen as a denial of a "basic right" [8]; not having access on demand is seen as being cut off from the information age, from the "two-fold emancipation ... from the limited nature of exchanges with his or her (immediate) fellows, and ... from the multiple servitude of distance in time and space" [9]. Like computer literacy a decade ago a new goal for education is being advocated (see also the definition of what being "well educated" will mean in the schools of the year 2000 cited at the start of this paper): "not knowing how to use the Internet will be as grave a deficiency as not knowing how to read" [10].

This statement was made by a businessman, not an educator. But clearly, the "superhighway" impulse is shaping new applications of communication and information technologies in schools. 


\section{Integrating information technology into education}

\section{"Just-in-time" learning}

Another idea is becoming more and more prominent in corporate settings and in large-scale training enterprises: the idea of "just-in-time" learning, where the learner, usually at his or her workplace and even while carrying out his or her ordinary work, has access to learning support when it is perceived to be useful. This impulse is driven by financial motivations to a great extent, in that it is assumed such workplace-based training will reduce costs associated with "going away" to traditional training courses, and also that it will result in more efficient training given the proximity of need, training, and opportunity for transfer.

This impulse is already suggesting changes for secondary education. The just-in-time approach implies that more and more responsibility comes to the individual in deciding when a learning episode is necessary and what resources are most appropriate for it, and that the responsibility of the trainer and employer will shift to that of provider of a range of learning resources and opportunities [11]. This approach also by definition calls for sophisticated resources and the use of communications technologies. Secondary school education is being called upon to prepare students for this type of future; to "learn the survival skills that will keep them employable through life" which will be heavily based on, in a self-directed way, "learning how to learn in the electronic workplace" [11].

\section{COUNTER-BALANCE: THE SCHOOL AND ORGANIZATIONAL CONSTRAINTS}

Societal impulses such as the five noted above do have a strong influence on what happens in the school with respect to communications and information technologies. But not as much as they might. The school organization serves as a solid resisting wall to rapid change impulses, a phenomenon which has been well documented in many countries and contexts. Space restraints only allow a summary of points here.

\section{Organizational constraints in the school system}

One cluster of organizational factors that are constraining the deployment of the current impulses related to equity and mobility, learning in cyberspace, and just-in-time learning are those related to the organizational identity of the school as an institution, issues related to boundary articulation and domain determination [12]. Institutions have their own accountability and cultures and perimeters; "bringing the world 
into the school" or other similar paradigm shifts, no matter how compelling, do not fit with existing organizations and their ways of defining themselves if they imply other corridors of authority and decision making. And this is not a matter of "fault" or limited vision, but rather a general survival trait of benefiting from consistency and established roles and structures. Secondary schools not only reflect the general resistance of an institution to change (and perhaps to lose some of its control over itself) but also are limited by other real and on-going expectations of society that continue even as impulses come and go - that students will learn a particular curriculum, will pass their tests, will earn their diplomas, and will make an effective transition, in as efficient a way as possible into the workplace.

These expectations can come in direct conflict with the attempted execution of social impulses such as the five described above. We have seen this in our decade of experience with computers in schools: except for courses where using computers becomes part of the testable curriculum, computer use remains an option, an add-on, an experience most likely to be available to those fortunate enough to have a teacher motivated to extend or enrich traditional instruction with computer use. Teachers are too busy with the demands of the curriculum, of the upcoming examination, of the challenges involved with guidance and management of their students, to handle the changes needed to reorganize their teaching in order to exploit the potential benefits of technology.

\section{A new organizational constraint: the computer establishment in the school}

The above sorts of constraints within the school and school system are well known; a more recent constraint comes from within the computer-use sector in the school itself. In the decade that computers have been in secondary schools, most schools now have a well-defined computer course and teachers associated with those courses. The computer courses, called by many different names in different countries, require extensive use of the school computer laboratory, and the school computer coordinator now has a well-thought through system for managing the computer laboratory, its local-area network, its security, and its maintenance.

In this environment, the teacher who wishes to explore some application of computer use with his or her students in a subject area such as language or science has difficulty. The laboratory is booked and busy and may be in a location far-removed from subject-area classroom; how can some of the students use the computers as tools during their writing or 
science activities? How and when can the teacher explore new uses of the technology? Not while the students are present, surely; but this means late after school, and then it may be that the coordinator wishes to lock up.

These collisions are already well know with respect to the attempted integration of computers into traditional subject areas. Recently we have seen them take on a new form in the context of teachers wishing to make use of communications technologies in schools [13]. It is even more problematical to try to connect students to an external network service or system than it is to try to find a way for them to use the computer lab for a familiar task such as word processing. The computer coordinators are specialists now in information technologies and Local Area Networks (LANs), but may have no experience with wide-area networking and its tools and protocols. The school administrator has learned how to gauge costs of computers, but has no idea how to anticipate the costs of students and teachers "navigating the Information Superhighway".

We encountered these problems in considerable magnitude when we carried out a project in 1993 that involved stimulating communications technology use in various vocational-education schools [13]. Despite the fact that we offered the participating teachers two computers and modems each, one for school use and one for home use, the teachers ran into serious problems trying to make use of these computers for telecommunications uses. The insurance arrangements that some of the schools had required that all computers be in the computer laboratory; thus the teacher could not use his or her computer in the classroom or work with it there after school. In other schools, the computer coordinator did not want to deal with the maintenance of any computer system outside the one which had been chosen for the school; thus we had to purchase new systems, different for each school, to match the idiosyncrasies of their school configurations. Wide-area connections interfered with the LAN software in some of the schools, and disengaging a computer from the LAN to separate telecommunications use was also not well accepted. Schools did not have a way to separate telephone charges for telecommunications uses from other telephone charges; or budget procedures to approve a project when the cost of the project was not specified in detail in advance (difficult to do with on-line use: the more successful a project, the more use will occur); or procedures to reimburse teachers for the on-line charges they incurred at home in their on-line lesson preparation.

In time, these sorts of organizational barriers will sort themselves out into procedures such as now are in place for the mainstream computer laboratories in schools; but then the next opportunity made possible by 
technology (perhaps more use of video and audio-graphic conferencing?) will encounter a similar wave of organizational frustrations.

\section{NETWORKING: THE NEWEST SOCIETAL IMPULSE AND ITS CHANCES IN SECONDARY EDUCATION}

\section{Community networking}

A new impulse is developing momentum in society: the concept of networking. Networking is an interesting word, in that it is both a noun and a verb, and can be used to refer to human associations, computer associations, or both. Within its technical associations it is used to refer to a number of different types of systems. It is also a powerful metaphor, one becoming more and more compelling given the rapid rise in "virtual communities" made possible by communications technology. These range from the countless local or regional bulletin board networks to the discussion groups of strangers that somehow evolve a sense of community through on-line networks. Many times these on-line groups are loosely defined, with no articulation of membership criteria or even no real sense of who is moving in or out of the community. But the communities that are having a more profound effect are those in which the on-line communities are a defined group who enrich and extend themselves through their on-line interactions. These sorts of groups are proliferating among teachers.

The LABNET Project based at TERC in Boston is a prime example [14]. Over a two-year period, over 200 secondary-school physics teachers made use of computer networking to strengthen their human networking relative to their communal work on curriculum development in physics, and their participation in various classroom-based projects in which they tried out their new pedagogical ideas and then discussed their experiences on-line with their remote peers and with curriculum specialists and other "special guests" who joined the "virtual community".

The LabNet example is a type of networking which brings together a group of persons involved in the same educational task but who happen to be in different places. The PIT Schools Project in The Netherlands is another such example [15]. A different type of networking is "community networking", which often involve a wide ad hoc alliance of different groups from a single physical community--educators, community activists, local businessmen, parents, social service providers, government agencies, computer professionals, youth--interacting as peers via the framework of a "community network service" [16]. This model of a citizen's-based, 


\section{Integrating information technology into education}

geographically delimited community communication and information system has taken hold in hundreds of locations in the US and in many locations in Europe, New Zealand, Australia, Japan, Canada, and many other countries $[13,16,17]$. The technical device of a local BBS, a type of communication configuration, supports many of these, although others have much more complex technological aspects and more and more offer internetworking, most often via a gateway to the Internet system. The participatory-medium aspect of these networks, and the natural involvement of teacher and students within them, are bringing new "social and political architectures" [16], new partnerships, new interaction patterns, new access to education and training opportunities, and a new sense of community meeting place. They may also be stimulating a new type of locus of information and community centrality which used to be a role the school played in the community, but more and more has already been lost to shopping centres and other centres of gravity.

Thus there is some likelihood to believe that the impulse of networking, human networking amplified by technology, is an impulse that will take root in society and not be a passing cliche. What will be the result of networking when it confronts the organizational inertia of the school?

\section{The secondary school and networking: constraints or integration?}

The potential of technical networking to bring "virtual communities" into the school, parallel to the face-to-face communities available in the school, has been predicted to be a major development in education that is already well underway $[18,19]$. Teachers and school administrators are discovering the stimulation and benefits of being able to interact with a self-chosen group of their peers, at a time and place convenient to them via asynchronous communication, and are taking increasing advantage of these possibilities $[13,19]$. The engagement of students in distributed communities is consistently felt to be an enriching and stimulating learning experience [19].

The networked computer laboratory, for example, is not an appropriate environment for networking activities. Will networking make a difference in the secondary school? Will it trigger a new deployment of communications and information technology in the school?

The start will probably be modest and tangential, with teachers and students doing their networking outside of the regular class and even outside of the school. (This is the case now with the growth of community networking and with the current patterns of network access shown by teachers and students. Honey and Henrmquez, for example, found that the 
most-frequent hours in which US teachers made use of the Internet was between 23:00 and 24:00 [19]). Occasional networking episodes in schools will for students will at first be of the nature of "electronic field trips" for students, and thus peripheral, relative to tests and grades and other socially expected measures of performance. The sense of concern about the costs involved for students to become part of on-line communities in a meaningful sense will deter organizational acceptance. Because of this we predict that teachers and administrators will be first candidates for meaningful networking [13].

\section{Networking: integration, in time}

It is my firm belief, however, that networking will eventually be integrated into the fabric of secondary-school education, in a way that many other applications of information technology have not. Why?

One major reason is that it taps a basic human need and pleasure - to talk, to make contact, to feel acknowledged by a group. We have not touched these needs at all with most of our deployments of information technology in secondary schools. This, plus the feeling of control that people have when they communicate on-line - they can say what they want, they use the computer as an extension of their ideas - are, I believe, contributing to the explosive growth of technical networking for communication and community building world wide.

Networking is also an application of technology that brings benefits into the school without needing to be adapted to the school. The outlay is relatively simple (compared, for example, to a multi-media laboratory) and the engagement of the participant is intense. For students, communication and communication-technology handling skills are practised in a functional setting. Teachers can find new and interesting resources and obtain new ideas from their contacts with their other communities, and they can increase their range of whom they can turn to with questions and problems. They can set the time and frequency of their networking, they can easily drop out of unproductive groups and try new ones. For once, the impulses of society may be in tune with what is also perceived to be useful and attractive to teachers $[6,13]$. As has been said:

...there are two things that have to happen before an idea catches on. The idea should be good and it should fit with the temper of the age. (Jawaharla Nehru)

Community networking may be such an idea. It certainly fits with the temper of the age, particularly the impulses related to communication technology and the "superhighway" and the "global village" ideas of being 
flexible in place and time. It will probably not, in itself, revolutionalize the school. But it could be an application of technology in the secondary school that brings a new wave of interest, applications, and users. It may be a societal impulse which also becomes an educational impulse.

\section{FINALLY: BETTER SOFTWARE}

There is still a major need for good, easy-to-use, software to better support on-line communication. A user interface with at least some of the file-management functionalities of computer conferencing needs to be freely available, easy to install, and not require all participants to first be part of a complex and costly conferencing system [20]. But this is a topic for another reflection.

\section{REFERENCES}

1. Mecklenburger, J. (1994) The New Generation of American Schools. Inventing Tomorrow's Schools, 4 (2), 18-20.

2. Collis, B., \& Anderson, R. (1993) International assessment of functional computer literacy. Studies in Educational Evaluation, 19 (2), 213-232. (For a larger range of references to support the conclusions in this section as well as throughout the paper, consult the author. Space considerations only allow a small sample of references here).

3. Pelgrum, H., \& Plomp, Tj. (1991) The Use of Computers in Education Worldwide. Oxford: Pergamon Press.

4. Muffoletto, R. (1994) Technology and Restructuring: Constructing a Context. Educational Technology, 34 (2), 24-28.

5. Cuban, L. (1986) Teachers and Machines: The Classroom Uses of Technology Since 1920. New York: Teachers College Press.

6. Collis, B., \& de Vries, P. (1993) The Emerging Trans-European Network for Education and Training: Guidelines for Decision Makers. Report prepared under contract to the Task Force Human Resources, Education, Training and Youth, Commission of the European Community, Brussels. Report No, 92-001-NIT-109/NL (This report contains a summary of five years of Community initiatives in the area of applying telecommunications technologies to increase equity of educational opportunity and mobility to all Europeans). 
7. Fitzsimmons, E. (1993) Office of Science and Technology Policy. Washington, DC: Executive Office of the President.

8. Kapor, M. (1991) Civil liberties in Cyberspace. Scientific American, 265 (3), 116-120.

9. Balle, F. (1990) The Information Society, Schools, and the Media. In M. Eraut (Ed.), Education and the Information Society: A Challenge for European Policy (pp. 79-93). London: Cassell Educational Press.

10. From Investor's Business Daily, 4/14/94, p. 4; a typical source of this sort of statement.

11. Romiszowski, A. (1990) Shifting Paradigms in Education and Training: What is the Connection with Telecommunications? Educational Technology and Training International, 27 (3), 233-237.

12. Donaldson, J. (1991) Boundary articulation, domain determination, and organizational learning in distance education: Practical opportunities and research needs. Distance Education Symposium: Selected Papers. Part 3. ACSDE Research Monograph. Number 9. University Park: PA: The American Center for the Study of Distance Education.

13. Collis, B., Veen, W. \& de Vries, P. (1993) Towards a Communication and Information System for Education in The Netherlands: The CISO Project. The Hague: PTT Telecom.

14. Ruopp, R., Gal, S., Drayton, B., \& Pfister, M. (1993) LabNet: Toward a Community of Practice. Hillsdale, NJ: Lawrence Erlbaum Associates.

15. Collis, B. (1994) A Triple Innovation in The Netherlands: Supporting a New Curriculum with New Technologies through a New Kind of Strategy for Teacher Networking. In press.

16. Schuler, D. (1994) Community Networks: Building a New Participatory Medium. Communications of the ACM, 37 (1), 39-51.

17. Communications Canada (1992) The Information Society: New Media ... New Choices. Ottawa: Minister of Supply and Services.

18. Dede, C. (1994) Swimming in a Sea of Information: The Future of Education in an Information Age. Presentation at the Global Village Schools National Conference, Atlanta.

19. Honey, M., \& Henrmquez, M. (1993) Telecommunications and K-12 Educators: Findings from a National Survey. New York: Bank Street College of Education. 
20. Collins, D., \& Bostock, S. J. (1993) Educational Effectiveness and the Computer Conferencing Interface. Educational Training and Technology International, 30 (4), 334-342.

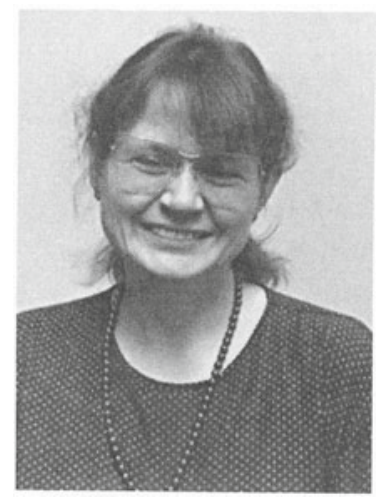

Betty Collis is a Canadian who since 1988 has been a member of the Faculty of Educational Science and Technology of the University of Twente in The Netherlands. Her PhD was in the area of measurement and evaluation of computer applications in education, and since the late 1970s she has been active in numerous international projects in this area. She is particularly interested in the many different and complex factors that influence the usability of a technology in education, ranging from those at the micro level, relating to the design of the instrumentation itself, to the macro level, at which social, cultural and political influences strongly shape the direction and nature of usage. Currently, she is focusing most directly on applications of and issues relating to communications technologies in education. 